\title{
BMJ Open The association between daily physical activity and plasma B-type natriuretic peptide in patients with glucose intolerance: a cross-sectional study
}

\author{
Hidetaka Hamasaki, ${ }^{1,2}$ Hidekatsu Yanai, ${ }^{1}$ Masafumi Kakei, ${ }^{2}$ Mitsuhiko Noda, ${ }^{3}$ \\ Osamu Ezaki ${ }^{4}$
}

To cite: Hamasaki $\mathrm{H}$, Yanai $\mathrm{H}$, Kakei $\mathrm{M}$, et al. The association between daily physical activity and plasma B-type natriuretic peptide in patients with glucose intolerance: a cross-sectional study. BMJ Open 2015;5: e006276. doi:10.1136/ bmjopen-2014-006276

- Prepublication history for this paper is available online. To view these files please visit the journal online (http://dx.doi.org/10.1136/ bmjopen-2014-006276).

Received 4 August 2014 Revised 16 December 2014 Accepted 18 December 2014

CrossMark

For numbered affiliations see end of article.

Correspondence to Dr Hidekatsu Yanai; dyanai@hospk.ncgm.go.jp

\section{ABSTRACT}

Objectives: In spite of accumulating evidences suggesting an inverse association between insulin resistance and plasma B-type natriuretic peptide (BNP) levels, the effect of daily physical activity on plasma BNP in individuals with glucose intolerance remains unknown. We investigated the association of physical activity level (PAL) with plasma BNP in patients with impaired fasting glucose, impaired glucose tolerance and type 2 diabetes.

Design: Cross-sectional study.

Setting: Outpatients visiting the National Center for Global Health and Medicine Kohnodai Hospital.

Participants: A total of 60 patients with glucose intolerance who did not take any hypoglycaemic agents, cholesterol-lowering agents and antihypertensive agents were recruited. Patients who were diagnosed as having heart failure and renal impairment, engaged in sports-like exercise and resistance training were excluded.

Primary outcome measures: PAL was objectively measured by a triaxial accelerometer. The association between PAL and plasma BNP levels was assessed by multiple regression analysis.

Results: PAL was positively correlated with plasma BNP levels $(r=0.296, p=0.021)$. PAL was still significantly correlated with plasma BNP levels after adjustment for age $(\beta=0.290, p=0.014)$, and adjustment for age and body mass index ( $\beta=0.282, p=0.018$ ). Plasma BNP levels were inversely correlated with serum insulin levels $(r=-0.350$, $p=0.006$ ) and homeostasis model assessment-estimated insulin resistance (HOMA-IR; $r=-0.363, p=0.004)$. Serum insulin levels (mean $\pm S D, 8.1 \pm 6.4 \mu \mathrm{U} / \mathrm{mL}$ ) and HOMA-IR $(2.4 \pm 1.9)$ in the high-BNP group were significantly lower than those $(11.2 \pm 7.4 \mu \mathrm{U} / \mathrm{mL}$ and $3.7 \pm 3.0$, respectively) in the low-BNP group.

Conclusions: Our findings propose the possibility that plasma BNP may be increased by daily physical activity and BNP is associated with insulin resistance.

\section{INTRODUCTION}

B-type natriuretic peptide (BNP) belongs to the cardiac natriuretic peptide family which are released from the heart in response to

\section{Strengths and limitations of this study}

- This study provides novel data: objectively measured light-intensity daily physical activity using a triaxial accelerometer is positively associated with plasma B-type natriuretic peptide (BNP) levels in patients with glucose intolerance.

- Our study precisely evaluated an association between daily physical activity and plasma BNP levels, by recruiting drug-naive patients who were not engaged in sports-like exercise.

- Previous studies reported an inverse association between plasma BNP levels and markers for insulin resistance in healthy participants. To the best of our knowledge, our study is the first to show a significant association between plasma BNP levels and insulin resistance in patients with glucose intolerance.

- Among the limitations are the small sample size and cross-sectional design which do not allow us to establish any causal relationship.

- Even a triaxial accelerometer may lead to an underestimation or overestimation of energy expenditure. It can not be denied that the energy expenditure assessed by a triaxial accelerometer differs from the true amounts.

pressure and volume overload. ${ }^{1}$ Plasma BNP and N-terminal proBNP (Nt-proBNP) are increased with the severity of left ventricular dysfunction and/or hypertrophy; therefore, it has become a useful biomarker for the diagnosis and prognosis of heart failure with or without type 2 diabetes. ${ }^{2-7}$

Plasma BNP levels have been reported to be inversely related to the body mass index (BMI) and waist circumference in individuals without heart failure. ${ }^{8}{ }^{9}$ Very recently, Olsen et $a l^{10}$ reported that Nt-proBNP was significantly lower in individuals with the metabolic syndrome as compared with those without the metabolic syndrome. In their study, the Nt-proBNP levels were inversely correlated with BMI, waist circumference, serum 
cholesterol and triglyceride, plasma glucose and insulin, independently of age and gender. ${ }^{10}$ These results suggest that BNP is beneficially associated with obesity and obesity-related metabolic disorders.

Low physical activity and a sedentary lifestyle induce the development of type 2 diabetes, and also deteriorate glucose control in patients with type 2 diabetes. ${ }^{11}{ }^{12}$ Exercise such as bicycle and hand-grip exercise has been reported to acutely increase plasma BNP levels with exercise intensity, in healthy individuals. ${ }^{13}{ }^{14}$ However, the effect of daily physical activity on plasma BNP levels remains obscure. To the best of our knowledge, there were no previous studies that investigated the association between daily physical activity and plasma BNP levels in patients with glucose intolerance.

We studied the association of physical activity level (PAL), which was evaluated objectively by using a triaxial accelerometer, with plasma BNP levels, in patients with impaired fasting glucose (IFG), impaired glucose tolerance (IGT) and type 2 diabetes. Furthermore, we elucidated the correlations of plasma BNP levels with metabolic parameters in patients with such glucose intolerance.

\section{MATERIAL AND METHODS}

\section{Study protocol and participants}

We recruited study participants with glucose intolerance who did not take any hypoglycaemic agents or cholesterol-lowering agents from outpatients who visited the Department of Internal Medicine, National Center for Global Health and Medicine Kohnodai Hospital, between August 2012 and December 2013 (inclusion criteria). Briefly, we determined the existence of glucose intolerance in our outpatients and also diagnosed participants as having type 2 diabetes, IFG and IGT by performing the $75 \mathrm{~g}$ oral glucose tolerance test (OGTT) and the measurement of glycated haemoglobin (HbAlc), fasting plasma glucose (FPG), casual plasma glucose and $2 \mathrm{~h}$ values in the OGTT. The participants were diagnosed as having type 2 diabetes according to diagnostic criteria set to serum levels of HbA1c $\geqq 6.5 \%$, FPG $\geqq 126 \mathrm{mg} / \mathrm{dL}$, casual plasma glucose $\geqq 200 \mathrm{mg} / \mathrm{dL}$ and $2 \mathrm{~h}$ values in the OGTT $\geqq 200 \mathrm{mg} / \mathrm{dL}$. ${ }^{15}$ The participants were defined as having IFG and IGT according to FPG levels $110 \mathrm{mg} / \mathrm{dL}$ to $125 \mathrm{mg} / \mathrm{dL}$, or $2 \mathrm{~h}$ values in the OGTT of $140 \mathrm{mg} / \mathrm{dL}$ to $199 \mathrm{mg} / \mathrm{dL} .{ }^{15}$ To understand the effects of daily physical activity such as non-exercise activity thermogenesis $(\mathrm{NEAT})^{16}$ on BNP and metabolic parameters, participants who were engaged in sports-like exercise and resistance training were excluded (exclusion criteria). Participants with heart failure and renal impairment were also excluded (exclusion criteria).

\section{Anthropometric and physiological measurements}

Height and weight were measured using a rigid stadiometer and scales (DP-7100PW, Yamato Co, Ltd, Hyogo, Japan). Waist circumference around the navel was measured with a metal anthropometric tape while participants were standing and breathing out. BMI was calculated as the body weight in kilograms divided by the height in metres squared. Blood pressure was measured with participants in a seated position using an automatic sphygmomanometer (HEM-762, Omron Co, Ltd, Kyoto, Japan).

\section{Physical activity measurement}

Daily physical activity was measured using a triaxial accelerometer (Active Style Pro HJA-350IT, Omron Co, Ltd, Kyoto, Japan), $74 \times 46 \times 34 \mathrm{~mm}$ and weighing $60 \mathrm{~g}$ including batteries. The study's participants wore the accelerometer on the left side of the waist. Anteroposterior, mediolateral and vertical acceleration measurements were obtained during each physical activity at a rate of $32 \mathrm{~Hz}$ to 12-bit accuracy. Each of three signals from the triaxial accelerometer was passed through a high-pass filter with a cut-off frequency of $0.7 \mathrm{~Hz}$ to remove the gravitational acceleration component. The ratios of unfiltered to filtered total acceleration (TAU/TAF) and filtered vertical and horizontal acceleration (VAF/HAF) were calculated to determine the cut-off value for the classification of locomotive activities and non-locomotive activities such as household and occupational activities, which resulted in an almost $100 \%$ accurate demarcation for the daily 11 different activities. ${ }^{17}$ Furthermore, metabolic equivalent values (METs) determined by this triaxial accelerometer have been reported to be closely correlated with METs calculated by using energy expenditure (EE) measured by indirect calorimetry. ${ }^{17} 18$

The study's participants wore the accelerometer on the left side of the waist for 7 consecutive days, and physical activities were recorded. They were requested to wear the accelerometer except under special circumstances such as sleeping, bathing and during aquatic activities. Activity data were stored on a minute-by-minute basis and were downloaded to a personal computer before analysis. We excluded days on which the participants did not wear the accelerometer for more than $8 \mathrm{~h}$ from the data for analysis.

Basal metabolic rate (BMR) was estimated from a multiple regression equation including age, sex, height and ideal body weight (IBW) as variables; the equation was as follows: BMR $(\mathrm{kcal} /$ day $)=((0.1283+0.0481 \times \mathrm{IBW}(\mathrm{kg})$ $+0.0234 \times$ height $\quad(\mathrm{cm})-0.0138 \times$ age $\quad$ (year $)-0.5473 \times$ sex coefficient (man: 1, woman:2) $\times 293) .{ }^{19}$ Total energy expenditure (TEE) was calculated by a manufactured regression equation using METs assessed by the triaxial accelerometer. ${ }^{18}$ PAL was calculated by the following equation: $\mathrm{PAL}=\mathrm{TEE} / \mathrm{BMR} \cdot{ }^{20}$

\section{Blood examination, BNP measurements}

After a $12 \mathrm{~h}$ overnight fast, blood samples were taken from the antecubital vein and collected into tubes. We measured FPG, HbAlc and serum insulin. FPG was measured using an enzymatic method (Wako Pure Chemical Industries, Osaka, Japan). Serum insulin and HbAlc were measured by automated ELISAs (TOSOH, Tokyo, 
Japan). We used homeostasis model assessment-estimated insulin resistance (HOMA-IR) as the marker for insulin resistance. ${ }^{21}$ Plasma BNP (BNP 1-32) levels were measured using a specific immunoradiometric assay for human BNP (ARCHITECT BNP-JP, ABBOTT JAPAN Co, Ltd, Tokyo, Japan). ${ }^{22}$ Imprecision studies yielded withinrun CVs of 1.1 to $5.1 \%$ and total CVs of 2.3 to $5.3 \%$ using human plasma based multiconstituent controls at concentrations of 92,500 and $3500 \mathrm{ng} / \mathrm{L}{ }^{22}$

\section{Statistical analysis}

Data were expressed as the mean \pm SD. Correlations among BNP, age, BMI, waist circumference, blood pressure, FPG, HbA1c, serum insulin levels, HOMA-IR and PAL were assessed by using Spearman's rank correlation coefficient. Multiple regression analysis was performed to test the independent correlation of PAL with plasma BNP levels. We divided participants into the high-BNP group $(\geqq 8.0 \mathrm{pg} / \mathrm{mL})$ and the low-BNP group $(<8.0 \mathrm{pg} / \mathrm{mL})$ by the median values of BNP. Differences in serum insulin levels, HOMA-IR and PAL between the high-BNP group and the low-BNP group were analysed by the Mann-Whitney $\mathrm{U}$ test. The statistical analyses were performed by using SPSS V.19 (IBM Co, Ltd, Chicago, USA). A p Value $<0.05$ was considered to be statistically significant.

\section{RESULTS}

We recruited 60 participants (28 men and 32 women) by the inclusion and exclusion criteria for participation in this study. Table 1 presents the clinical characteristics of studied participants. Thirty-one participants were diagnosed as having type 2 diabetes, 14 participants were with IFG and 15 participants were with IGT. The range of age in the study's participants was 27-74 years.

PAL evaluated by a triaxial accelerometer was significantly and positively correlated with plasma BNP levels $(\mathrm{r}=0.296, \mathrm{p}=0.021$; figure 1$)$. Age was correlated with

\begin{tabular}{lc}
$\begin{array}{l}\text { Table } 1 \text { Clinical and biochemical characteristics of } \\
\text { participants }\end{array}$ \\
\hline $\mathbf{N}$ & 60 \\
\hline Age (years) & $54.7 \pm 12.2$ \\
Height $(\mathrm{cm})$ & $161.3 \pm 8.9$ \\
Weight $(\mathrm{kg})$ & $69.2 \pm 16.1$ \\
BMI $\left(\mathrm{kg} / \mathrm{m}^{2}\right)$ & $26.5 \pm 5.1$ \\
Waist circumference $(\mathrm{cm})$ & $92.4 \pm 13.1$ \\
Systolic blood pressure $(\mathrm{mm} \mathrm{Hg})$ & $128.8 \pm 17.6$ \\
Diastolic blood pressure $(\mathrm{mm} \mathrm{Hg})$ & $80.5 \pm 12.5$ \\
Fasting plasma glucose $(\mathrm{mg} / \mathrm{dL})$ & $122.9 \pm 25.6$ \\
HbA1c $(\%)$ & $6.7 \pm 1.1$ \\
BNP $(\mathrm{pg} / \mathrm{mL})$ & $14.0 \pm 14.6$ \\
Serum insulin $(\mu \mathrm{U} / \mathrm{mL})$ & $9.6 \pm 6.9$ \\
HOMA-IR & $3.02 \pm 2.62$ \\
\hline Da &
\end{tabular}

Data are expressed as the mean $\pm S D$.

BMI, body mass index; BNP, B-type natriuretic peptide; $\mathrm{HbA1c}$, glycated haemoglobin; HOMA-IR, homeostasis model

assessment-estimated insulin resistance.
BMI $(\mathrm{r}=-0.431, \mathrm{p}<0.001)$, but not correlated with PAL $(\mathrm{r}=0.096, \mathrm{p}=0.462)$. BMI was not correlated with PAL $(\mathrm{r}=$ $-0.11, \mathrm{p}=0.4)$. The values of PAL showed a normal distribution ( $\mathrm{p}=0.453$ by the Shapiro-Wilk test); however, plasma BNP levels showed non-normal distribution $(\mathrm{p}<0.001)$. Multivariate logistic regression was used after controlling simultaneously for potential confounders. The variables considered in the models were age (continuous) and BMI (continuous). To adjust the correlation between PAL and plasma BNP by age and BMI, plasma BNP values were logarithmically transformed. PAL was still significantly correlated with $\log$ plasma BNP levels after adjustment for age $(\beta=0.290, p=0.014)$, and adjustment for age and BMI $(\beta=0.282, p=0.018)$.

Table 2 shows the correlations of plasma BNP levels with clinical and metabolic parameters in participants.

There were no significant correlations of plasma BNP levels with systolic and diastolic blood pressure, FPG and HbA1c. Plasma BNP levels were significantly and inversely correlated with BMI, waist circumference, serum insulin levels and HOMA-IR and were positively correlated with age. Significant correlations of plasma BNP levels with serum insulin $(\beta=-0.204, p=0.119)$ and HOMA-IR $(\beta=-0.271, p=0.129)$ were lost after adjusting for PAL.

To further understand the associations of plasma BNP levels with insulin resistance, we examined the differences in serum insulin levels and HOMA-IR between the high-BNP group and the low-BNP group (figure 2). Serum insulin levels $($ mean $\pm \mathrm{SD}, 8.1 \pm 6.4 \mathrm{U} / \mathrm{mL})$ in the high-BNP group were significantly lower than those $(11.2 \pm 7.4 \mathrm{U} / \mathrm{mL})$ in the low-BNP group. HOMA-IR (2.4 $\pm 1.9)$ in the high-BNP group was also significantly lower than that $(3.7 \pm 3.0)$ in the low-BNP group. We also analysed the relationship between quartiles of plasma BNP versus serum insulin and HOMA-IR (figure 3). We found a significant influence of plasma BNP on both serum insulin ( $p=0.018$ by the Kruskal-Wallis ANOVA) and HOMA-IR ( $\mathrm{p}=0.018)$. The serum insulin level in the highest plasma BNP quartile was significantly lower than in the lowest plasma BNP quartile. HOMA-IR in the

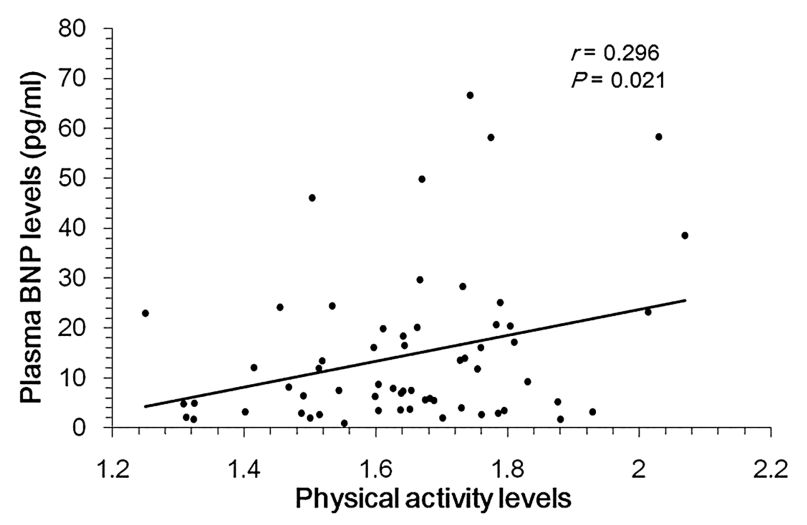

Figure 1 Correlation of physical activity level and plasma BNP levels in 60 participants. $r$ Indicates the correlation coefficient analysed by Spearman's rank correlation coefficient. 
Table 2 Correlations of plasma BNP levels to clinical and metabolic parameters

\begin{tabular}{lcr}
\hline & $\begin{array}{c}\text { Correlation } \\
\text { coefficient }\end{array}$ & \multicolumn{1}{c}{$\begin{array}{l}\text { p } \\
\text { Value }\end{array}$} \\
\hline Age (years) & 0.441 & $<0.001$ \\
BMI (kg/m²) & -0.256 & 0.048 \\
Waist circumference $(\mathrm{cm})$ & -0.279 & 0.031 \\
Systolic blood pressure & 0.175 & 0.185 \\
(mm Hg) & & \\
Diastolic blood pressure & -0.070 & 0.598 \\
(mm Hg) & & \\
Fasting plasma glucose & -0.237 & 0.068 \\
(mg/dL) & & \\
HbA1c (\%) & 0.050 & 0.705 \\
Serum insulin ( $\mu \mathrm{U} / \mathrm{mL})$ & -0.350 & 0.006 \\
HOMA-IR & -0.363 & 0.004 \\
\hline A &
\end{tabular}

A statistical analysis was performed by Spearman's rank correlation coefficient.

BMI, body mass index; BNP, B-type natriuretic peptide; HbA1c, glycated haemoglobin; HOMA-IR, homeostasis model assessment-estimated insulin resistance.

highest plasma BNP quartile was also significantly lower than in the lowest plasma BNP quartile.

The mean \pm SD of plasma BNP levels in patients with type 2 diabetes ( 13 men and 18 women), IFG ( 5 men and 9 women) and IGT (10 men and 5 women) were $14.3 \pm 13.5 \mathrm{pg} / \mathrm{mL}, \quad 12.9 \pm 17.2 \mathrm{pg} / \mathrm{mL}$ and 14.5 $\pm 15.1 \mathrm{pg} / \mathrm{mL}$, respectively. The mean $\pm \mathrm{SD}$ of $\mathrm{PAL}$ in patients with type 2 diabetes, IFG and IGT were 1.66 $\pm 0.22,1.65 \pm 0.15$ and $1.66 \pm 0.20$, respectively. There were no significant differences in plasma BNP levels and PAL among patients with type 2 diabetes, IFG and IGT.

\section{DISCUSSION}

Recent cross-sectional studies reported that plasma BNP or NT-proBNP levels were inversely associated with visceral fat, ${ }^{23} \mathrm{BMI}$, waist circumference and serum insulin levels. ${ }^{9}{ }^{10}$ However, the effect of daily physical activity on plasma BNP levels remains unknown.
Previous cross-sectional studies have not ever been performed by using individuals with glucose intolerance as our study participants. In the present study, we examined the correlation of daily physical activity, measured objectively by a triaxial accelerometer with plasma BNP levels, in patients with prediabetes and early untreated type 2 diabetes.

This study demonstrates a significant and positive association between daily physical activity and plasma BNP levels, and also an inverse association of plasma BNP levels with BMI, waist circumference, serum insulin levels and HOMA-IR. Previous studies reported that exercise such as bicycle and hand-grip exercise acutely increase plasma BNP levels with exercise intensity in healthy individuals. ${ }^{13}{ }^{14}$ However, the effect of daily physical activity on plasma BNP levels remains unknown. It is noteworthy that we could observe a significant effect of low-intensity daily physical activity, including walking, dishing and washing clothes, defined as NEAT, ${ }^{15}$ on plasma BNP levels. Chainani-Wu et al previously conducted a nested prospective cohort study of a lifestyle intervention to understand the effects of lifestyle on BNP. They observed that the change in BNP for 3 months was significantly associated with the change in exercise score, even after controlling for the percentage of change in BMI, which agreed with a significant and positive correlation between PAL and plasma BNP levels after adjustment by age and BMI in our study. At 3 months in their study, they found an inverse association of the change in BNP with the changes in BMI and insulin, ${ }^{24}$ suggesting a significant association between $\mathrm{BNP}$ and insulin resistance.

An inverse association between natriuretic peptide and obesity and/or insulin resistance has been established. $^{8-10} 232526$ However, controversy exists as to this association. Lower natriuretic peptide levels in obese individuals has been reported to be due to increased clearance by the natriuretic peptide receptors (NPR)-C abundantly expressed in adipose tissue, and also due to decreased natriuretic peptide release from the heart. $^{27-29}$ BNP binds to NPR on adipose tissue and stimulates lipolysis, ${ }^{30}$ regulates adipose tissue by activation
Figure 2 Serum insulin levels (A) and the homeostatic model assessment-estimated insulin resistance (HOMA-IR) $(B)$ in the high-BNP group $(n=30)$ and the low-BNP group $(n=30)$. Data are mean values $\pm S D$. We divided participants into the high-BNP group ( $\geqq 8.0 \mathrm{pg} / \mathrm{mL})$ and the low-BNP group ( $<8.0 \mathrm{pg} / \mathrm{mL})$ by the median values of BNP. Differences in serum insulin levels and HOMA-IR between the high-BNP group and the low-BNP group were analysed by the Mann-Whitney $U$ test.
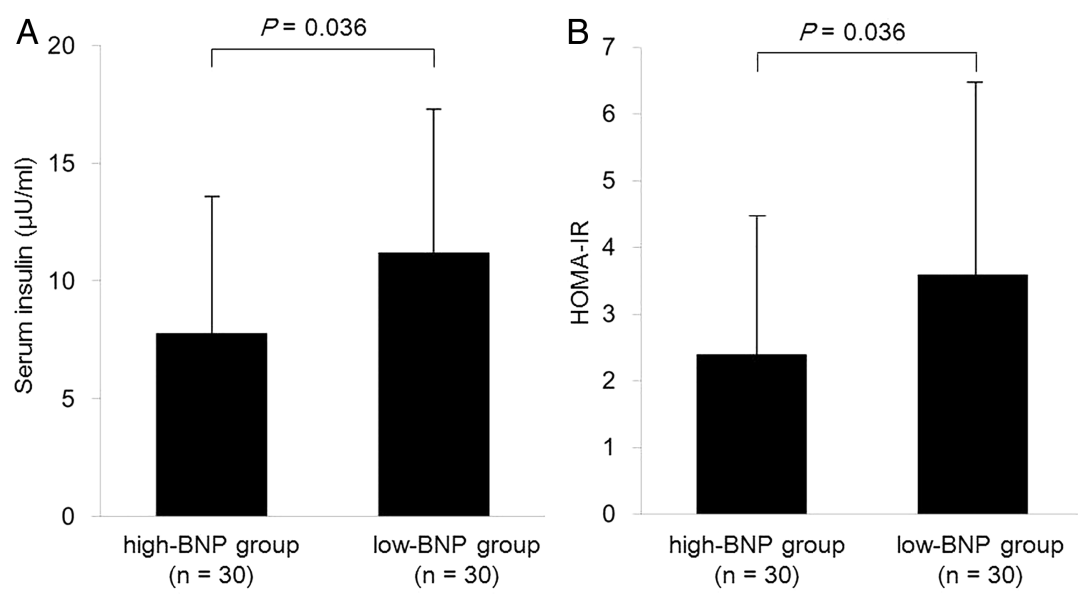
Figure 3 Serum insulin levels

(A) and homeostatic model assessment-estimated insulin resistance (HOMA-IR) (B) in each plasma BNP quartiles. Q1 is the lowest quartile and Q4 is the highest quartile. Boxes indicate medians and quartiles; whiskers indicate the lowest and highest values. We found a significant influence of plasma BNP on both serum insulin ( $p=0.018$ by the Kruskal-Wallis ANOVA) and HOMA-IR ( $p=0.018)$. The difference between Q1 and Q2-4 was statistically analysed by Scheffe's F Test.
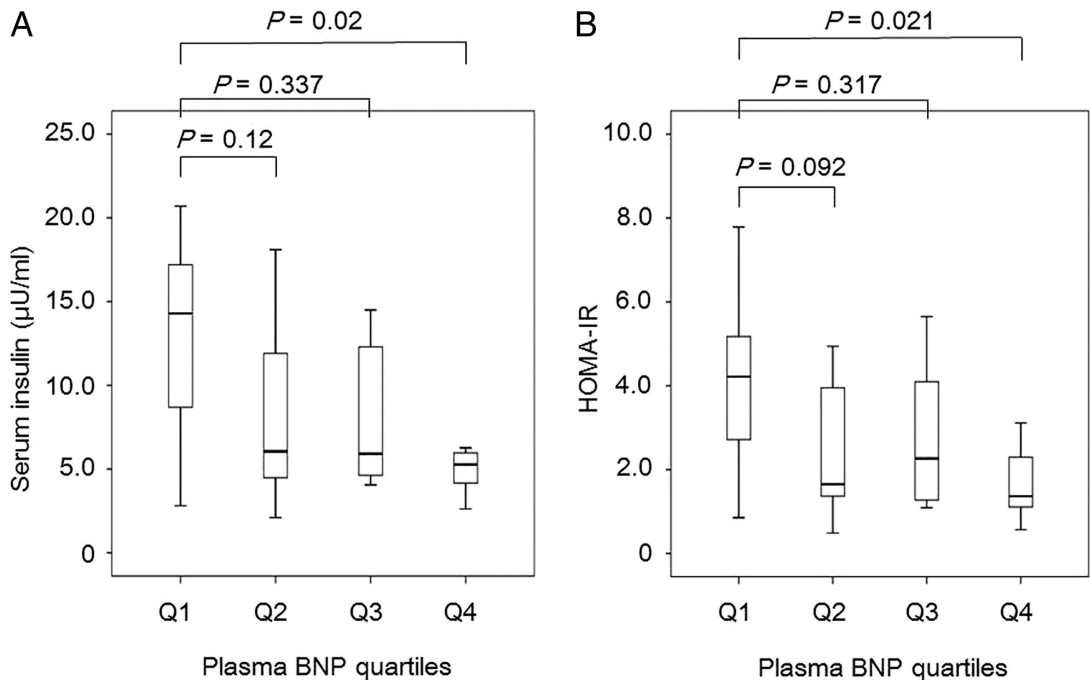

of proliferator-activated receptor $\gamma(\operatorname{PPAR} \gamma)$ gene expres$\operatorname{sion}^{31}$ and increases adiponectin secretion, ${ }^{32}$ which improves insulin resistance.

Evidences for the association of glucose intolerance with BNP are very limited. A previous study reported that diabetes was significantly associated with low plasma BNP levels (adjusted OR 1.51 (1.00 to 2.27) for men; adjusted OR 1.95 (1.26 to 3.02 ) for women). ${ }^{8}$ However, the underlying mechanisms for low BNP levels in patients with impaired glucose metabolism remain unknown. In this study, PAL was positively correlated with plasma BNP levels, which were inversely correlated with the marker for insulin resistance. Furthermore, serum insulin levels and HOMA-IR were significantly lower in the high-BNP group as compared with those in the low-BNP group. BMI and waist circumference were also correlated with plasma BNP levels. Increased PAL may be associated with a reduction of BMI and waist circumference, which improves insulin resistance and induces elevation of plasma BNP, due to the decreased clearance by NPR-C abundantly expressed in adipose tissue. Otherwise, increased plasma BNP may ameliorate insulin resistance through various mechanisms, such as reduced oxidative stress, ${ }^{33}$ decreased systemic inflammation, ${ }^{34}$ stimulated lipolysis, ${ }^{30}$ activation of PPAR $\gamma$ gene expression and increased adiponectin secretion. ${ }^{31} 32$ Recently, increased plasma BNP levels and/or biological activity could also improve insulin resistance by increasing mitochondrial fat oxidative capacity in white and brown fat, as well as in skeletal muscle. ${ }^{35}$ However, the cardiac ejection fraction is also inversely related to plasma BNP levels but is not beneficial, ${ }^{2-7}$ and plasma BNP levels are reported to increase lipolysis ${ }^{37}$ and to be positively associated with insulin resistance. ${ }^{38}$ The relationships among PAL, BNP and insulin resistance in impaired glucose metabolism remain largely unknown. We should perform further studies, preferably using a greater number of patients with glucose intolerance.

There are several limitations that need to be considered when interpreting the results of this study. This is a cross-sectional study, which limits inferences of causality and its direction. Although we controlled for some confounding factors (age, sex, BMI, engagement in sportslike exercise or resistance training and medication), other factors such as genetic variation were not taken into account. Furthermore, we studied only patients with IFG, IGT and type 2 diabetes, and therefore our conclusions cannot apply to healthy populations. A heterogeneous group of individuals with IFG, IGT and type 2 diabetes was examined. We could not mention that the associations between BNP and physical activity or insulin resistance were the same in the three groups. We will study these associations by using a great number of patients with each type of glucose intolerance in the future. The triaxial accelerometer is an extensively validated device for evaluating physical activity under free living conditions; ${ }^{39-41}$ however, Leenders et at ${ }^{42}$ indicated that the predictive equations based on the relationship between acceleration and energy expenditure (EE) during locomotive movements led to an underestimation and overestimation of TEE. It is possible that EE and PAL assessed by a triaxial accelerometer differ from the true amounts of EE and PAL.

In conclusion, we found a significant and positive association between PAL and plasma BNP levels in patients with prediabetes and early untreated type 2 diabetes. Plasma BNP levels were inversely associated with insulin resistance. Our findings propose the possibility that BNP could be increased by daily physical activity and plasma BNP is beneficially associated with insulin resistance.

\section{Author affiliations}

${ }^{1}$ Department of Internal Medicine, National Center for Global Health and Medicine Kohnodai Hospital, Chiba, Japan

${ }^{2}$ Division of Complementary Medicine, First Department of General Medicine, Saitama Medical Center, Jichi Medical University School of Medicine,

Saitama, Japan

${ }^{3}$ Department of Diabetes Research, Diabetes Research Center, National Center for Global Health and Medicine, Tokyo, Japan

${ }^{4}$ Department of Human Health and Design, Faculty of Human Life and Environmental Sciences, Showa Women's University, Tokyo, Japan 
Contributors $\mathrm{HH}, \mathrm{HY}$ and $\mathrm{OE}$ conceived and designed the study. $\mathrm{HH}$ and MN performed the study. $\mathrm{HH}, \mathrm{HY}$ and MK analysed the data, interpreted the results and wrote the manuscript. $\mathrm{HH}$ and $\mathrm{HY}$ also discussed the analyses, interpretation and presentation and participated in the drafting of the manuscript.

Funding This study was supported by a grant from the National Center for Global Health and Medicine (25-203)

Competing interests None.

Patient consent Obtained.

Ethics approval The study was approved by the Medical Ethics Committee of the National Center for Global Health and Medicine (reference number NCGM-G-001212)

Provenance and peer review Not commissioned; externally peer reviewed.

Data sharing statement No additional data are available.

Open Access This is an Open Access article distributed in accordance with the Creative Commons Attribution Non Commercial (CC BY-NC 4.0) license which permits others to distribute, remix, adapt, build upon this work noncommercially, and license their derivative works on different terms, provided the original work is properly cited and the use is non-commercial. See: http:// creativecommons.org/licenses/by-nc/4.0/

\section{REFERENCES}

1. Gardner DG, Chen S, Glenn DJ, et al. Molecular biology of the natriuretic peptide system: implications for physiology and hypertension. Hypertension 2007;49:419-26.

2. Maeda K, Tsutamoto T, Wada A, et al. High levels of plasma brain natriuretic peptide and interleukin- 6 after optimized treatment for heart failure are independent risk factors for morbidity and mortality in patients with congestive heart failure. J Am Coll Cardiol 2000;36:1587-93

3. Wang TJ, Larson MG, Levy D, et al. Plasma natriuretic peptide levels and the risk of cardiovascular events and death. $N$ Engl $J$ Med 2004;350:655-63.

4. Alehagen $U$, Lindstedt $G$, Levin LA, et al. Risk of cardiovascular death in elderly patients with possible heart failure. B-type natriuretic peptide (BNP) and the aminoterminal fragment of ProBNP (N-terminal proBNP) as prognostic indicators in a 6-year follow-up of a primary care population. Int $J$ Cardiol 2005;100:125-33.

5. Kroon $\mathrm{MH}$, van den Hurk $\mathrm{K}$, Alssema $\mathrm{M}$, et al. Prospective associations of B-type natriuretic peptide with markers of left ventricular function in individuals with and without type 2 diabetes an 8-year follow-up of the Hoorn Study. Diabetes Care 2012;35:2510-14

6. Olsen $\mathrm{MH}$, Wachtell $\mathrm{K}$, Tuxen $\mathrm{C}$, et al. $\mathrm{N}$-terminal pro-brain natriuretic peptide predicts cardiovascular events in patients with hypertension and left ventricular hypertrophy: a LIFE study. $J$ Hypertens 2004;22:1597-604.

7. Schirmer $\mathrm{H}$, Omland $\mathrm{T}$. Circulating $\mathrm{N}$-terminal pro-atrial natriuretic peptide is an independent predictor of left ventricular hypertrophy in the general population. The Troms $\varnothing$ Study. Eur Heart $J$ 1999;20:755-63.

8. Wang TJ, Larson MG, Levy D, et al. Impact of obesity on plasma natriuretic peptide levels. Circulation 2004;109:594-600.

9. Koizumi M, Watanabe $\mathrm{H}$, Kaneko $\mathrm{Y}$, et al. Impact of obesity on plasma B-type natriuretic peptide levels in Japanese community-based subjects. Heart Vessels 2012;27:287-94.

10. Olsen $\mathrm{MH}$, Hansen TW, Christensen MK, et al. N-terminal pro brain natriuretic peptide is inversely related to metabolic cardiovascular risk factors and the metabolic syndrome. Hypertension 2005;46:660-6.

11. Hamilton MT, Hamilton DG, Zderic TW. Role of low energy expenditure and sitting in obesity, metabolic syndrome, type 2 diabetes, and cardiovascular disease. Diabetes 2007;56:2655-67.

12. Avery L, Flynn D, van Wersch A, et al. Changing physical activity behavior in type 2 diabetes: a systematic review and meta-analysis of behavioral interventions. Diabetes Care 2012;35:2681-9.

13. Barletta G, Stefani L, Del Bene R, et al. Effects of exercise on natriuretic peptides and cardiac function in man. Int $J$ Cardiol 1998;65:217-25
14. Nielsen HB, De Palo EF, Meneghetti M, et al. Circulating immunoreactive proANP1-30 and proANP31-67 responses to acute exercise. Regul Pept 2001;99:203-7.

15. American Diabetes Association. Diagnosis and classification of diabetes mellitus. Diabetes Care 2010;33:S62-9.

16. Levine JA. Non-exercise activity thermogenesis (NEAT). Nutr Rev 2004;62:S82-97.

17. Oshima Y, Kawaguchi K, Tanaka S, et al. Classifying household and locomotive activities using a triaxial accelerometer. Gait Posture 2010;31:370-4.

18. Ohkawara K, Oshima $\mathrm{Y}$, Hikihara $\mathrm{Y}$, et al. Real-time estimation of daily physical activity intensity by a triaxial accelerometer and a gravity-removal classification algorithm. Br J Nutr 2011;105:1681-91

19. Ganpule AA, Tanaka S, Ishikawa-Takata K, et al. Interindividual variability in sleeping metabolic rate in Japanese subjects. Eur J Clin Nutr 2007;61:1256-61.

20. [No authors listed]. Energy and protein requirements. Report of a joint FAO/WHO/UNU Expert Consultation. World Health Organ Tech Rep Ser 1985;724:1-206.

21. Matthews DR, Hosker JP, Rudenski AS, et al. Homeostasis model assessment: insulin resistance and beta-cell function from fasting plasma glucose and insulin concentrations in man. Diabetologia 1985;28:412-19.

22. Mongia SK, La'ulu SL, Apple FS, et al. Performance characteristics of the Architect brain natriuretic peptide (BNP) assay: a two site study. Clin Chim Acta 2008;391:102-5.

23. Neeland IJ, Winders BR, Ayers CR, et al. Higher natriuretic peptide levels associate with a favorable adipose tissue distribution profile. J Am Coll Cardiol 2013;62:752-60.

24. Chainani-Wu N, Weidner G, Purnell DM, et al. Relation of B-type natriuretic peptide levels to body mass index after comprehensive lifestyle changes. Am J Cardiol 2010;105:1570-6.

25. Mehra MR, Uber PA, Park MH, et al. Obesity and suppressed B-type natriuretic peptide levels in heart failure. J Am Coll Cardiol 2004;43:1590-5.

26. McCord J, Mundy BJ, Hudson MP, et al. Relationship between obesity and B-type natriuretic peptide levels. Arch Intern Med 2004;164:2247-52.

27. Dessì-Fulgheri $P$, Sarzani $R$, Tamburrini $P$, et al. Plasma atrial natriuretic peptide and natriuretic peptide receptor gene expression in adipose tissue of normotensive and hypertensive obese patients. J Hypertens 1997;15:1695-9.

28. Das SR, Drazner MH, Dries DL, et al. Impact of body mass and body composition on circulating levels of natriuretic peptides: results from the Dallas Heart Study. Circulation 2005;112:2163-8.

29. Costello-Boerrigter LC, Burnett JC Jr. A new role for the natriuretic peptides: metabolic regulators of the adipocyte. J Am Coll Cardiol 2009;53:2078-9.

30. Sengenès $\mathrm{C}$, Berlan $\mathrm{M}$, De Glisezinski I, et al. Natriuretic peptides: a new lipolytic pathway in human adipocytes. FASEB $J$ 2000;14:1345-51.

31. Miyashita K, Itoh $\mathrm{H}$, Tsujimoto $\mathrm{H}$, et al. Natriuretic peptides/cGMP/ cGMP-dependent protein kinase cascades promote muscle mitochondrial biogenesis and prevent obesity. Diabetes 2009;58:2880-92.

32. Tsukamoto O, Fujita M, Kato M, et al. Natriuretic peptides enhance the production of adiponectin in human adipocytes and in patients with chronic heart failure. J Am Coll Cardiol 2009;53:2070-7.

33. Rajagopalan S, Kurz S, Münzel T, et al. Angiotensin II-mediated hypertension in the rat increases vascular superoxide production via membrane NADH/NADPH oxidase activation. Contribution to alterations of vasomotor tone. J Clin Invest 1996;97:1916-23.

34. Moro C, Klimcakova E, Lolmède K, et al. Atrial natriuretic peptide inhibits the production of adipokines and cytokines linked to inflammation and insulin resistance in human subcutaneous adipose tissue. Diabetologia 2007;50:1038-47.

35. Bordicchia M, Liu D, Amri EZ, et al. Cardiac natriuretic peptides act via p38 MAPK to induce the brown fat thermogenic program in mouse and human adipocytes. J Clin Invest 2012;122:1022-36

36. Engeli S, Birkenfeld AL, Badin PM, et al. Natriuretic peptides enhance the oxidative capacity of human skeletal muscle. J Clin Invest 2012;122:4675-9.

37. Polak J, Kotrc M, Wedellova Z, et al. Lipolytic effects of B-type natriuretic peptide 1-32 in adipose tissue of heart failure patients compared with healthy controls. J Am Coll Cardiol 2011;58:1119-25.

38. Tekes S, Cikim AS. The association of brain natriuretic peptide and insulin resistance in obesity-related hypertension. J Hum Hypertens 2007;21:546-50. 
39. Plasqui G, Bonomi AG, Westerterp KR. Daily physical activity assessment with accelerometers: new insights and validation studies. Obes Rev 2013;14:451-62.

40. Midorikawa T, Tanaka S, Kaneko K, et al. Evaluation of low-intensity physical activity by triaxial accelerometry. Obesity 2007;15:3031-8.
41. Ekelund U, Sjöström M, Yngve A, et al. Physical activity assessed by activity monitor and doubly labeled water in children. Med Sci Sports Exerc 2001;33:275-81.

42. Leenders NY, Sherman WM, Nagaraja HN. Energy expenditure estimated by accelerometry and doubly labeled water: do they agree? Med Sci Sports Exerc 2006;38:2165-72. 